\title{
Protective effects of Polygonatum sibiricum polysaccharide on acute heart failure in rats ${ }^{1}$
}

Xiuying Zhu', Wei Wu", Xiyan Chen"', Feiyun Yang'I', Jianxin Zhang ${ }^{\prime V}$, Jingyu Hou'

'MD, Department of Emergency Medicine, The First Affiliated Hospital of Xinxiang Medical University, China. Design of the study, critical revision, final approval.

"MD, Department of Emergency Medicine, The First Affiliated Hospital of Xinxiang Medical University, China. Acquisition of data, critical revision, final approval.

'"'MD, Department of Emergency Medicine, The First Affiliated Hospital of Xinxiang Medical University, China. Statistical analysis, critical revision, final approval.

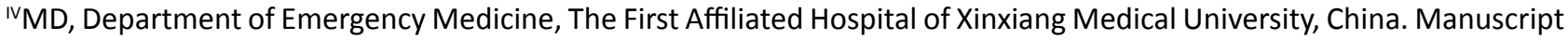
preparation, critical revision, final approval.

\section{Abstract}

Purpose: To investigate the protective effects of Polygonatum sibiricum polysaccharide (PSP) on acute heart failure (AHF) in rats.

Methods: Sixty rats were randomly divided into control, model, and low-, middle- and highdose PSP groups, 12 rats in each group. The low-, medium- and high-dose PSP groups were intragastrically administrated with 100, 200 and $400 \mathrm{mg} / \mathrm{kg}$ PSP for 5 days, respectively. On the sixth day, the AHF model was established by intraperitoneal injection of adriamycin. After $24 \mathrm{~h}$, the cardiac function, serum biochemical indexes, myocardial ATPase and succinate dehydrogenase levels and apoptosis related protein expressions were determined.

Results: Compared with model group, in high-dose PSP group the heart rate, left ventricular systolic pressure, $\pm \mathrm{dp} / \mathrm{dt}_{\text {max }}$, serum superoxide dismutase level, myocardial $\mathrm{Na}^{+}-\mathrm{K}^{+}$-ATPase, $\mathrm{Ca}^{2+}-\mathrm{Mg}^{2+}$-ATPase and succinate dehydrogenase levels and myocardial $\mathrm{Bcl}-2$ and Caspase-3 protein expression levels were significantly increased $(P<0.05)$, the left ventricular end diastolic pressure, serum CTnI, CK-MB, TNF- $\alpha, \mathrm{IL}-6$, malondialdehyde and nitric oxide levels and myocardial Bax and cleaved Caspase-3 protein expression levels were significantly decreased $(P<0.05)$.

Conclusions: Polysaccharide can prevent the acute heart failure induced by adriamycin. The mechanism may be related to its anti-oxidative stress, anti-inflammation and inhibition of cardiac myocyte apoptosis.

Key words: Heart Failure. Polygonatum. Polysaccharides. Oxidative Stress. Apoptosis. Rats. 


\section{Introduction}

Heart failure is a common clinical disease, with incidence rising year by year. Acute heart failure (AHF) refers to the insufficient tissue and organ perfusion or acute congestion syndrome caused by obvious and sudden decrease in cardiac output due to acute heart disease ${ }^{1}$. In clinic, the acute left ventricular failure is the more common form of $\mathrm{AHF}^{2}$. AHF often occurs on the basis of original chronic heart failure, with an aggravation or sudden onset. Most of AHF patients are complicated by organic cardiovascular disease before disease onset ${ }^{3}$. AHF can be characterized by contractile heart failure or diastolic heart failure. It often endangers the life of patients, and the first aid is often needed for treating this disease ${ }^{4}$. Rhizoma polygonati is the dry rhizome of liliaceous plant Polygonatum kingianum Coll. et Hemsl. and $P$. cyrtomem. The main active ingredient of Rhizoma polygonati is the Polygonatum sibiricum polysaccharide (PSP) ${ }^{5}$. Studies show that, Rhizoma polygonati has the anti-tumor, antioxidant, anti-inflammatory, antibacterial, blood glucose and lipid regulating, anti-virus, immune enhancing functions ${ }^{6-9}$. It is found that, the bioactive polysaccharide can improve the cardiac function of model animals ${ }^{10,11}$. However, there is no report on the effect of PSP on AHF. In this study, the protective effects of PSP on adriamycin-induced AHF in rats and the underlying mechanisms were investigated. The objective was to provide an experimental basis for the clinical application of PSP to prevention of AHF.

\section{Methods}

This study was carried out in strict accordance with the recommendations in the Guide for the Care and Use of Laboratory
Animals of the National Institutes of Health. The animal use protocol has been reviewed and approved by the Institutional Animal Care and Use Committee of Xinxiang Medical University.

\section{Animals and treatment}

Sixty male Sprague Dawley rats (220260g; Henan Experimental Animal Center, Guangzhou, China) were randomly divided into control group, model group, and low-, medium- and high-dose PSP groups, 12 rats in each group. After weighing, the rats in low, medium- and high-dose PSP groups were intragastrically administrated with PSP (30\% content; Xi'an Senran Bioengineering Co., Ltd., Xi'an, China), with dose of 100, 200 and 400 $\mathrm{mg} / \mathrm{kg}$, respectively. The control and model groups were administrated with equal volume of normal saline. The administration was performed once per day, for continuous 5 days. On the sixth day, except for the control group, the other groups received intraperitoneal injection of adriamycin $(10 \mathrm{mg} / \mathrm{kg})$ for 1 times, to establish the AHF model.

\section{Detection of cardiac function of rats}

After $24 \mathrm{~h}$ from injection of adriamycin, the rats were anaesthetized using $20 \%$ urethane, with dose of $5 \mathrm{ml} / \mathrm{kg}$. The rats were fixed in supine position. The cervical median incision was made, followed by tracheal intubation. The right carotid artery was isolated. After heparinization, the ventricular catheter was inserted into the left ventricle through the right carotid artery, and was connected to the biological signal recorder. The cardiac function indexes including heart rate (HR), left ventricular systolic pressure (LVSP), left ventricular end diastolic pressure (LVEDP) and maximum left ventricular systolic/diastolic rate $\left( \pm \mathrm{d} p / \mathrm{d} t_{\text {max }}\right)$ were recorded. 


\section{Determination of serum biochemical indexes}

After detection of cardiac function, the blood was taken from the femoral artery aorta. After centrifuging at $2500 \mathrm{r} / \mathrm{min}$ for 10 $\mathrm{min}$, the serum was obtained. The serum levels of cardiac troponin I (cTnl), creatine kinase isoenzyme (CK-MB), tumor necrosis factor- $\alpha$ (TNF- $\alpha)$, interleukin-6 (IL-6), superoxide dismutase (SOD), malondialdehyde (MDA) and nitric oxide (NO) were determined accordance to the instructions of kits. The kits were provided by Sigma-Aldrich Corp. (MO, USA).

Determination of heart weight index and left ventricular weight index

Heart of rats was taken. After absorb the water using filter paper, the heart was weighed. Then, the left ventricle was separated and weighed. The heart weight index and left ventricular weight index were calculated by ratio of heart weight to body weight and ratio of left ventricular weight to body weight, respectively.

Determination of myocardial ATPase and succinate dehydrogenase levels

Myocardial tissue homogenate was prepared. The content of protein was determined using Coomassie bright blue method. The levels of myocardial ATPase and succinate dehydrogenase were determined according to the instructions of the kits (Beijing Zhongshan Golden Bridge Biotechnology Co., Ltd., Beijing, China).

Determination of myocardial B-cell lymphoma-2, Bcl-2 associated $X$ and cysteinyl aspartate specific proteinase- 3 protein expressions

Myocardial tissue was homogenized. The protein was extracted using and cell lysate, and it concentration was determined. The expressions levels of B-cell lymphoma-2 (Bcl2), Bcl-2 associated X (Bax), cysteinyl aspartate specific proteinase-3 (Caspase-3) and cleaved Caspase- 3 protein in myocardial tissue were detected using western blot assays. $\beta$-actin was used as the internal reference. The ratio of integral optical density of target protein to $\beta$-actin presented the relative expression level of target protein. The experiment procedures were in accordance to the instructions of kits (Beijing Jinghongda Biotechnology Co., Ltd., Beijing, China).

\section{Statistical analysis}

Statistical analysis was performed using SPSS 23.0 software (SPSS Inc., Chicago, IL, USA). The data were presented as mean $\pm S D$. The difference among different groups was analyzed using one-way analysis of variance with $q$ test. The relationships among different indexes were investigated using Pearson correlation analysis. $\mathrm{P}<0.05$ presented statistically significant.

\section{- Results}

\section{General situation of rats}

During the experiment, no rat died in each group. After establishment of AHF model, there was no significant difference of body weight, heart weight index or left ventricular weight index among different groups ( $P>0.05)$ (Figure 1). There was no obvious side effect in each group. 


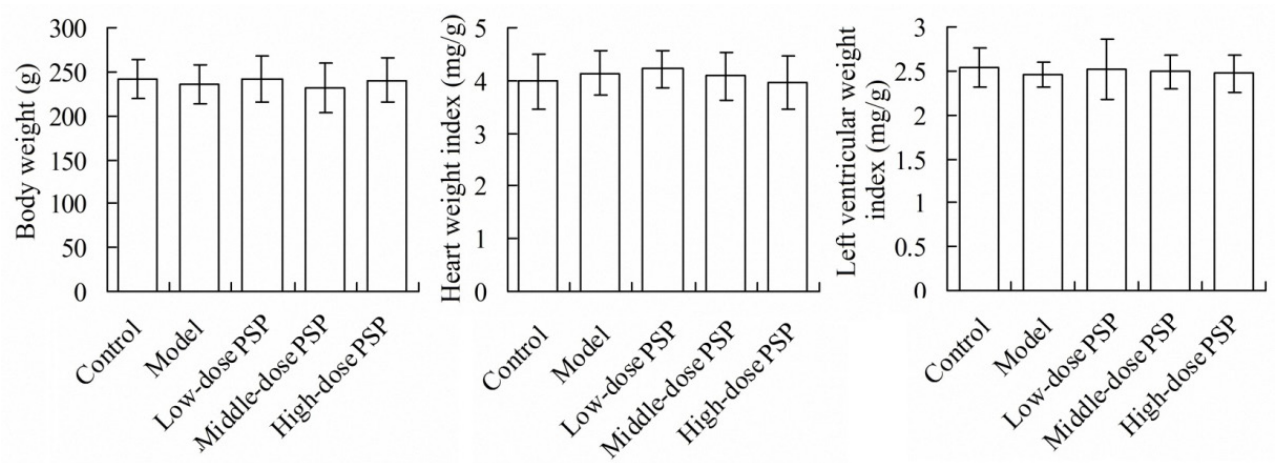

Figure 1 - Body weight, heart weight index and left ventricular weight index in 5 groups. PSP, Polygonatum sibiricum polysaccharide.

\section{Cardiac function indexes in 5 groups}

In model group the LVEDP was $11.04 \pm 3.31$ $\mathrm{mmHg}$, which was significantly higher than $6.23 \pm 1.68 \mathrm{mmHg}$ in control group. The LVEDP in high-dose PSP group was $8.38 \pm 2.11 \mathrm{mmHg}$, which was significantly lower than model group $(\mathrm{P}<0.05)$. In model group the HR, LVSP, $+d p /$ $\mathrm{d} t_{\max }$ and $-\mathrm{d} p / \mathrm{d} t_{\max }$ were $281.26 \pm 29.48$ beats/ $\min , 95.27 \pm 14.45 \mathrm{mmHg}, 4123.12 \pm 1029.42$ $\mathrm{mmHg} / \mathrm{s}$ and $3256.12 \pm 667.56 \mathrm{mmHg} / \mathrm{s}$, respectively, which were significantly lower than $332.45 \pm 27.37$ beats/min, $133.93 \pm 16.93$ $\mathrm{mmHg}, \quad 7056.34 \pm 1306.51 \mathrm{mmHg} / \mathrm{s}$ and $6002.31 \pm 1012.22 \mathrm{mmHg} / \mathrm{s}$ in control group, respectively. Those in high-dose PSP group were $328.71 \pm 35.03$ beats $/ \mathrm{min}, 130.34 \pm 22.18$ $\mathrm{mmHg}, \quad 6452.22 \pm 1023.72 \mathrm{mmHg} / \mathrm{s}$ and $5488.32 \pm 902.45 \mathrm{mmHg} / \mathrm{s}$, respectively, which were significantly higher than model group, respectively $(P<0.05)$ (Figure 2$)$.
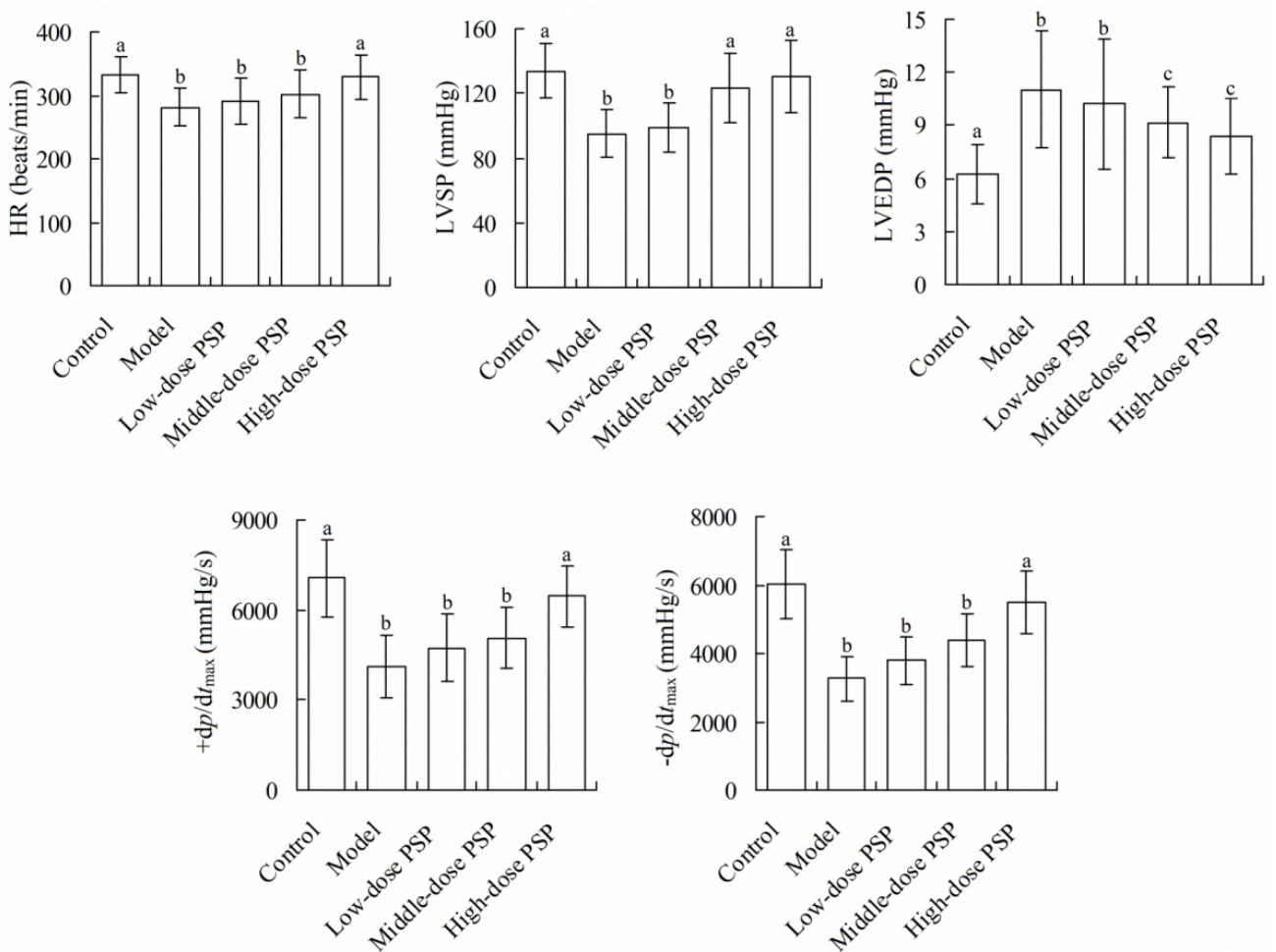

Figure 2 - Cardiac function indexes in 5 groups. For each index, values with different characters $(a, b, c . . . .$. meant significant difference among different groups $(\mathrm{P}<0.05)$. PSP, Polygonatum sibiricum polysaccharide; $H R$, hear rate; LVSP, left ventricular systolic pressure; LVEDP, left ventricular end diastolic pressure. 
In model group the serum cTnl and $\mathrm{CK}-\mathrm{MB}$ levels were $2.01 \pm 0.42 \mathrm{ng} / \mathrm{ml}$ and 101.07 $\pm 17.11 \mathrm{U} / \mathrm{L}$, respectively, which were significantly higher than $0.45 \pm 0.12 \mathrm{ng} / \mathrm{ml}$ and $30.05 \pm 6.06 \mathrm{U} / \mathrm{L}$ in control group, respectively $(P<0.05)$. The serum $\mathrm{CTnI}$ and CK-MB levels in high-dose PSP group were $0.67 \pm 0.13 \mathrm{ng} / \mathrm{ml}$ and $45.11 \pm 6.01 \mathrm{U} / \mathrm{L}$, respectively, which were significantly lower than those in model group, respectively $(P<0.05)$ (Figure 3$)$.
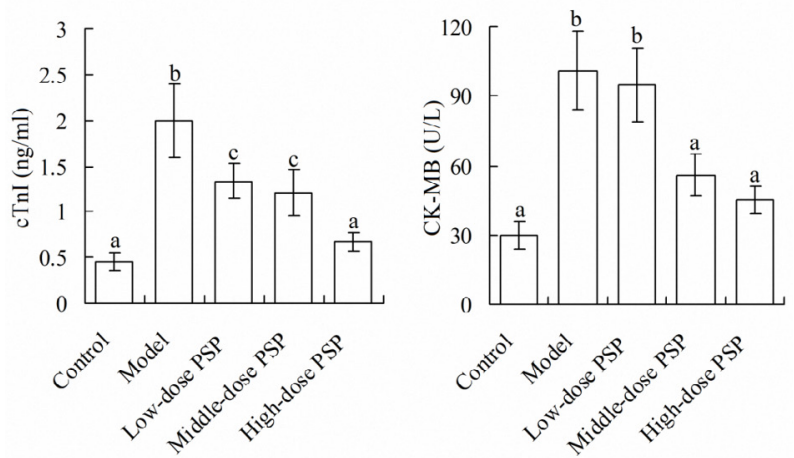

Figure 3 - Serum cTnl and CK-MB levels in 5 groups. For each index, values with different characters $(a, b, c . . . .$.$) meant significant difference among$ different groups $(P<0.05)$. PSP, Polygonatum sibiricum polysaccharide; $c T n l$, cardiac troponin I; CK-MB, creatine kinase isoenzyme.

\section{Serum TNF- $\alpha$ and IL-6 levels in 5 groups}

As shown in Figure 4, in model group the serum TNF- $\alpha$ and IL- 6 levels were $156.05 \pm 20.06 \mathrm{ng} / \mathrm{L}$ and $230.05 \pm 39.84 \mathrm{ng} / \mathrm{L}$, respectively, which were significantly higher than $58.11 \pm 10.02 \mathrm{ng} / \mathrm{L}$ and $99.97 \pm 34.04 \mathrm{ng} / \mathrm{L}$ in control group, respectively $(P<0.05)$. The serum TNF- $\alpha$ and IL- 6 levels in high-dose PSP group were $63.07 \pm 8.09 \mathrm{ng} /$ Land $102.02 \pm 22.89$ $\mathrm{ng} / \mathrm{L}$, respectively, which were significantly lower than those in model group, respectively $(P<0.05)$.
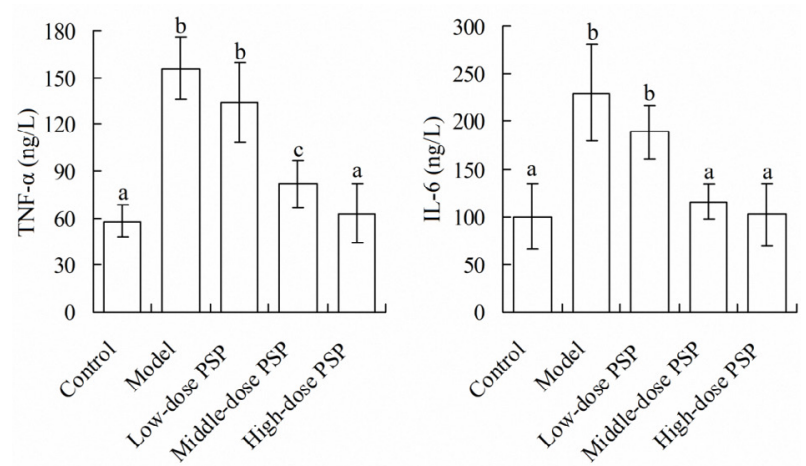

Figure 4 - Serum TNF- $\alpha$ and IL- 6 levels in 5 groups. For each index, values with different characters $(a, b, c . . . .$.$) meant significant difference among$ different groups $(\mathrm{P}<0.05)$. $\mathrm{PSP}$, Polygonatum sibiricum polysaccharide; TNF- $\alpha$, tumor necrosis factor- $\alpha$; IL-6, interleukin-6.

Serum SOD, MDA and NO levels in 5 groups

As shown in Figure 5, in model group the serum SOD level was $67.84 \pm 8.55$ $\mathrm{U} / \mathrm{ml}$, which was significantly lower than $122.47 \pm 18.37 \mathrm{U} / \mathrm{ml}$ in control group. The SOD level in high-dose PSP group was 102.27 \pm 18.93 $\mathrm{U} / \mathrm{ml}$, which was significantly higher than model group $(P<0.05)$. In model group the serum MDA and NO levels were 9.07 \pm 2.15 $\mu \mathrm{mol} / \mathrm{L}$ and $140.59 \pm 23.73 \mu \mathrm{mol} / \mathrm{L}$, respectively, which were significantly higher than $5.22 \pm 0.92$ $\mu \mathrm{mol} / \mathrm{L}$ and $44.45 \pm 7.47 \mu \mathrm{mol} / \mathrm{L}$ in control group, respectively. The serum MDA and NO levels in high-dose PSP group were 5.89 \pm 1.05 $\mu \mathrm{mol} / \mathrm{L}$ and $55.83 \pm 9.68 \mu \mathrm{mol} / \mathrm{L}$, respectively, which were significantly lower than model group, respectively $(P<0.05)$. 

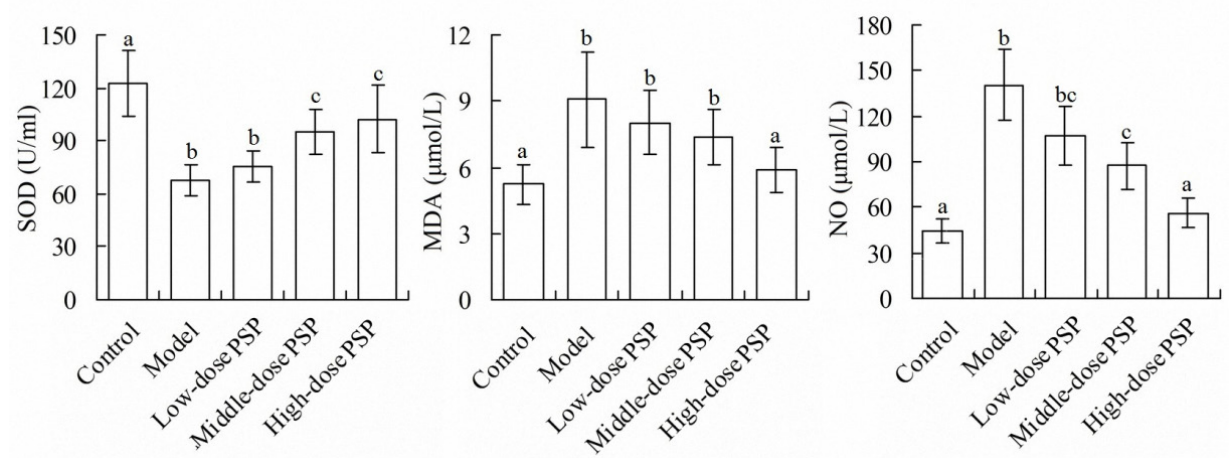

Figure 5 - Serum SOD, MDA and NO levels in 5 groups. For each index, values with different characters $(a, b, c . . . .$.$) meant significant difference among different groups (\mathrm{P}<0.05)$. PSP, Polygonatum sibiricum polysaccharide; SOD, superoxide dismutase; MDA, malondialdehyde; NO, nitric oxide.

Myocardial ATPase and succinate

dehydrogenase levels in 5 groups

Figure 6 showed that, in model group the myocardial $\mathrm{Na}^{+}-\mathrm{K}^{+}$-ATPase, $\mathrm{Ca}^{2+}-\mathrm{Mg}^{2+}-$ ATPase and succinate dehydrogenase levels were $2.35 \pm 0.57 \mu \mathrm{mol} / \mathrm{mg}, 1.93 \pm 0.44 \mu \mathrm{mol} / \mathrm{mg}$ prot and $65.26 \pm 10.03 \mathrm{U} / \mathrm{mg}$ prot, respectively, which were significantly lower than $5.24 \pm 0.77$ $\mu \mathrm{mol} / \mathrm{mg}$ prot, $4.38 \pm 0.67 \mu \mathrm{mol} / \mathrm{mg}$ prot and $113.84 \pm 16.63 \mathrm{U} / \mathrm{mg}$ prot in control group, respectively $(P<0.05)$. The myocardial $\mathrm{Na}^{+}-$ $\mathrm{K}^{+}$-ATPase, $\mathrm{Ca}^{2+}-\mathrm{Mg}^{2+}-$ ATPase and succinate dehydrogenase levels in high-dose PSP group were $4.97 \pm 0.82 \mu \mathrm{mol} / \mathrm{mg}$ prot, $3.81 \pm 0.69$ $\mu \mathrm{mol} / \mathrm{mg}$ prot and $105.48 \pm 15.82 \mathrm{U} / \mathrm{mg}$ prot, respectively, which were significantly higher than model group, respectively $(P<0.05)$.
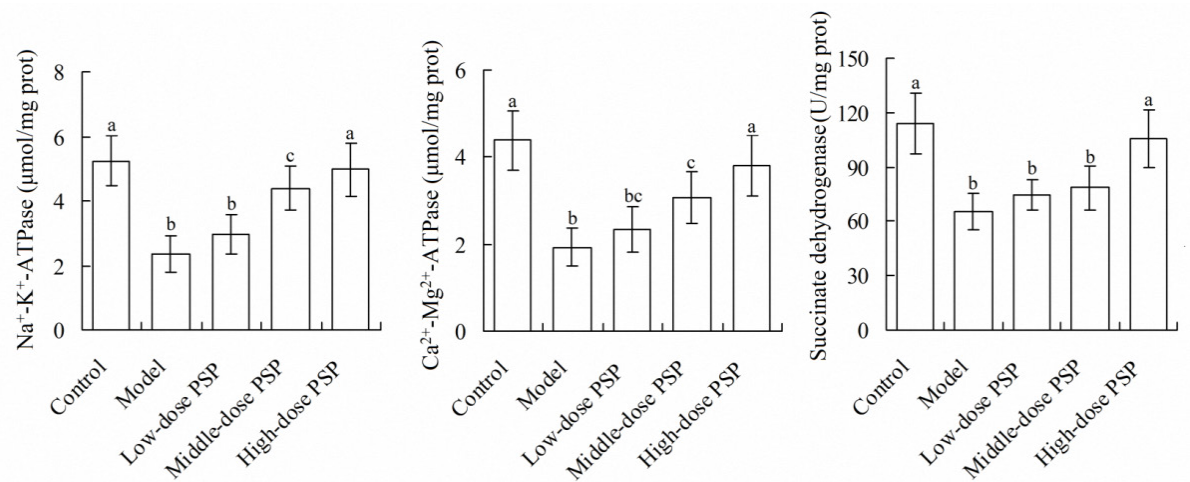

Figure 6 - Myocardial ATPase and succinate dehydrogenase levels in 5 groups. For each index, values with different characters $(a, b, c . . . .$.$) meant significant difference among different groups (P<0.05)$. PSP, Polygonatum sibiricum polysaccharide.

Myocardial Bcl-2, Bax and Caspase-3 protein expressions in 5 groups

As shown in Figure 7, the myocardial $\mathrm{Bcl}-2$ and Caspase-3 protein expression levels in model group $(\mathrm{BCl}-2 / \beta$-actin ratio, $0.52 \pm 0.13$; Caspase- $3 / \beta$-actin ratio, $0.28 \pm 0.17$ ) were significantly lower than those in control group (Bcl-2/ $\beta$-actin ratio, $0.93 \pm 0.21$; Caspase-3/ $\beta$ actin ratio, $0.98 \pm 0.26)$, respectively $(\mathrm{P}<0.05)$. Compared with model group, the $\mathrm{BCl}-2$ and Caspase-3 protein expression levels in highdose PSP group (Bcl-2/ $\beta$-actin ratio, 0.88 \pm 0.19 ; Caspase-3/ $\beta$-actin ratio, $0.81 \pm 0.15$ ) were 
significantly increased, respectively $(P<0.05)$. The myocardial Bax and cleaved Caspase-3 protein expression levels in model group (Bax/ $\beta$-actin ratio, 0.45 \pm 0.11 ; cleaved Caspase-3/ $\beta$ actin ratio, $1.21 \pm 0.21$ ) were significantly higher than those in control group (Bax/ $\beta$-actin ratio, $0.13 \pm 0.02$; cleaved Caspase- $3 / \beta$-actin ratio, $0.62 \pm 0.12)$, respectively. Compared with model group, the Bax and cleaved Caspase- 3 protein levels in high-dose PSP group (Bax/ $\beta$-actin ratio, $0.14 \pm 0.03$; cleaved Caspase-3/ $\beta$-actin ratio, $0.73 \pm 0.13$ ) were significantly decreased, respectively $(P<0.05)$.
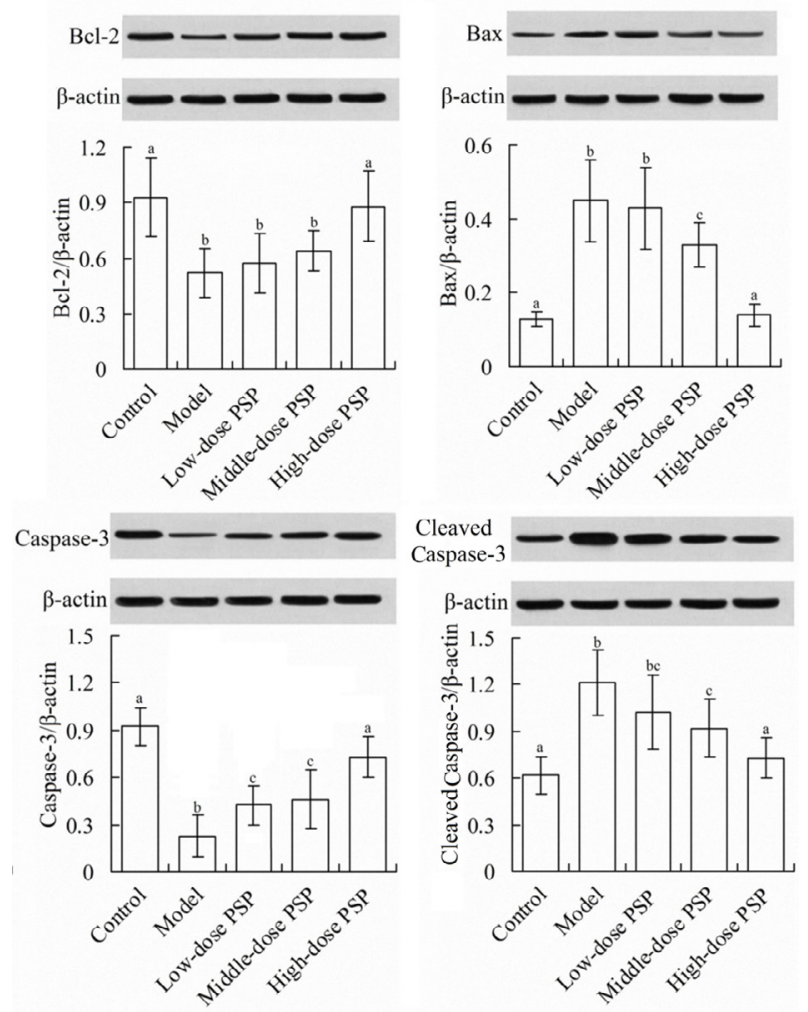

Figure 7 - Myocardial Bcl-2, Bax and Caspase-3 protein expressions in 5 groups. For each index, values with different characters $(a, b, c . . . .$. meant significant difference among different groups $(\mathrm{P}<0.05)$. $\mathrm{PSP}$, Polygonatum sibiricum polysaccharide; $\mathrm{Bcl}-2$, B-cell lymphoma-2; Bax, B-cell lymphoma-2 associated $\mathrm{X}$; Caspase-3, cysteinyl aspartate specific proteinase-3.

\section{Relationships among different indexes}

Pearson correlation analysis showed that, the serum SOD level was positively correlated with the succinate dehydrogenase level $(r=0.701, P<0.01)$. The serum cTnl level was positively correlated with the myocardial Bax protein level $(r=0.474, P<0.01)$. The serum TNF- $\alpha$ level was positively correlated with the myocardial Bax protein level $(r=0.583, P<0.01)$. The serum cTnl level was positively correlated with the serum TNF- $\alpha$ level $(r=0.369, P<0.01)$. There was no significantly correlation between each of other indexes $(P>0.05)$.

\section{Discussion}

Adriamycin can lead to the production of free radicals and cell oxidative damage in the body. The free radicals directly attack the membrane lipids, causing the changes in membrane structure and function ${ }^{12}$. The large dose of adriamycin can seriously inhibit the myocardial contractile function of rats, leading to the AHF. The main manifestations are the rapid decline of left ventricular systolic function, with significant decrease of $H R$, LVSP and $\pm \mathrm{d} p / \mathrm{d} t_{\max }$ in hemodynamics ${ }^{13}$. The adriamycin-induced AHF model is simple and easy to control, and is often used in the study of AHF. In this study, the adriamycininduced AHF model of rats was established, and the protective effects of PSP on AHF were investigated. Result showed that, compared with control group, in model group the LVEDP was significantly increased, and the HR, LVSP and $\pm \mathrm{d} p / \mathrm{d} t_{\text {max }}$ were significantly decreased. In addition, the levels of myocardial injury marker serum cTnl and CK-MB were significantly increased. This indicates that, the AHF model has been successfully constructed. Compared with model group, in the high-dose PSP group, the LVEDP was significantly decreased, and the HR, LVSP and $\pm d p / d t_{\text {max }}$ were significantly 
increased. In addition, the levels of serum cTnl and CK-MB were significantly decreased. This suggests that, the PSP can prevent the AHF induced by adriamycin. Our pre-experiments find that, if PSP is injected after AHF induction, the protective effects are not satisfactory. Therefore, only the pre-treatment with PSP can exert the protective effects on AHF.

Inflammatory reaction plays an important role in the occurrence, development and evolution of heart failure ${ }^{14}$. TNF- $\alpha$ is produced by macrophages, which can regulate the immune function of body. It promoted the function of $\mathrm{T}$ cells and other killer cells, and its level is also significantly increased in stress state ${ }^{15}$. IL- 6 is a cytokine secreted by activated macrophages, and has a wide range of biological effects in the body. It can be used as a marker of clinical and experimental heart failure ${ }^{16}$. In this study, the serum TNF- $\alpha$ and IL- 6 levels in model group were significantly higher than control group. This indicates that, adriamycin can induce the inflammatory reaction in the body. Compared with model group, the serum TNF- $\alpha$ and IL- 6 levels in high-dose PSP group were significantly decreased. This suggests that, PSP can alleviate the inflammatory reaction induced by adriamycin.

In this study, the serum MDA and NO levels in model group were significantly higher than those in control group, respectively, and the serum SOD level in model group was significantly lower than that in control group. This indicates that, the endogenous MDA and $\mathrm{NO}$ are excessively produced in AHF rats, and the free radical scavenging ability by SOD is reduced. NO is a highly reactive free radical that causes the damage and even denaturation and necrosis of cardiac myocytes ${ }^{17}$. The serum level of MDA reflects the degree of oxidative damage in the body ${ }^{18}$. SOD is the most important enzyme for scavenging oxygen free radicals in the body. It can effectively remove and terminate the chain reaction caused by superoxide anion. The activity of SOD indirectly reflects the body's ability in removing oxygen free radicals $^{19}$. Joe et $\mathrm{al}^{20}$ have used the lipopolysaccharide to stimulate peritoneal macrophages in rats and find that, NO can inhibit the activity of SOD in macrophages and increase the MDA production, resulting in lipid peroxidation and decreased myocardial contractile function. Results of this study showed that, compared with model group, in high-dose PSP group the serum SOD level was significantly increased, and the MDA and NO levels were significantly decreased. This indicates that, PSP can scavenge the oxygen free radicals, prevent their attack to cell membrane, and reduce lipid peroxidation damage, thus enhancing the myocardial contractility.

Adriamycin acts on the membrane of the cardiac myocytes, leading to the depolymerization the phospholipid mosaic protein in the membrane, increase of membrane permeability, and increase of the $\mathrm{Ca}^{2+}$ internal flow. At the same time, adriamycin can directly inhibit the activity of $\mathrm{Na}^{+}-\mathrm{K}^{+}$-ATPase, which decreases the $\mathrm{Na}^{+}-\mathrm{K}^{+}$ exchange, and increase the $\mathrm{Na}^{+}-\mathrm{Ca}^{2+}$ exchange. Therefore, the $\mathrm{Ca}^{2+}$ internal flow is increased, which induces the calcium overload, leading to the mitochondrial damage ${ }^{21}$. Mitochondria are important places for energy metabolism. The production and storage of ATP are carried out in mitochondria. When mitochondria are severely damaged, the ATP production decreases, resulting in decreased myocardial contractility ${ }^{22}$. Succinate dehydrogenase is a marker enzyme in the mitochondrial membrane of cardiac myocytes. It is one of the important enzymes for the electron transfering and oxidative phosphorylation in the energy metabolism of cardiac myocytes. Its activity reflects the energy metabolism of mitochondria in the cells ${ }^{23}$. In this study, the myocardial $\mathrm{Na}^{+}-\mathrm{K}^{+}$-ATPase, $\mathrm{Ca}^{2+}-\mathrm{Mg}^{2+}$-ATPase and succinate dehydrogenase levels in model 
group were significantly lower than control group. This indicates that, adriamycin can decrease the activity of ATPase and succinate dehydrogenase in cardiac myocytes, thus causing the decrease of cardiac function. Compared with model group, the myocardial $\mathrm{Na}^{+}-\mathrm{K}^{+}$-ATPase, $\mathrm{Ca}^{2+}-\mathrm{Mg}^{2+}$-ATPase and succinate dehydrogenase levels in high-dose PSP group were significantly increased. This suggests that, PSP can increase the activity of ATPase and succinate dehydrogenase in cardiac myocytes, thus improving the cardiac function.

It is found that, the adriamycin-induced myocardial injury is associated with apoptosis of cardiac myocytes, with a dose-effect relationship ${ }^{24}$. Among the known apoptosis regulators, the $\mathrm{Bcl}-2$ family plays a key role in apoptosis induced by various stimuli. The levels of $\mathrm{Bcl}-2$ and Bax protein are directly related to the regulation of apoptosis. The increased Bax promotes the cell apoptosis, and the increased $\mathrm{Bcl}-2$ inhibits the cell apoptosis ${ }^{25}$. Caspases are the promoter and executor of the cell apoptosis in mammalian, in which cleaved Caspase- 3 is the most critical apoptotic protease in the downstream of Caspases cascade $^{26}$. In addition, $\mathrm{Bcl}-2$ can block the activation of Caspase-3 (cleaved Caspase-3) by interfering with the release of cytochrome $C$, thus inhibiting the cell apoptosis. Bax enables cytochrome $C$ to pass through the mitochondrial membrane, which activates Caspase-9, and further activates Caspase-3, leading to the cell apoptosis ${ }^{27}$. Results of this study showed that, compared with control group, the myocardial $\mathrm{Bcl}-2$ protein expression level in model group was significantly decreased, and the Bax and cleaved Caspase-3 protein levels were significantly increased. This has further confirmed the proapoptotic effect of adriamycin on cardiac myocytes. Compared with model group, in high-dose PSP group the myocardial $\mathrm{Bcl}-2$ protein expression level was significantly increased, and the Bax and cleaved
Caspase-3 protein levels were significantly decreased. This indicates that, PSP can inhibit the apoptosis of cardiac myocytes induced by adriamycin, and its mechanism may be related to the increase of $\mathrm{Bcl}-2$ protein expression and decrease of Bax and cleaved Caspase- 3 protein expressions.

\section{Conclusions}

Polysaccharide can prevent the acute heart failure induced by adriamycin. The mechanism may be related to its anti-oxidative stress, anti-inflammation and inhibition of cardiac myocyte apoptosis. This study has provided an experimental basis for the clinical application of PSP to prevention of AHF. This study still has some limitations. Firstly, the apoptosis of myocardial cells had not been investigated using TUNEL staining. Secondly, the relationship analysis showed that, there was no significantly correlation among majority of indexes. The reason may be due to the relatively small sample size. In next studies, these issues should be solved to make the results more convincing.

\section{References}

1. Mueller C, Christ M, Cowie M, Cullen L, Maisel AS, Masip J, Miro O, McMurray J, Peacock FW, Price S, DiSomma S, Bueno H, Zeymer U, Mebazaa A; Acute Heart Failure Study Group of the ESC Acute Cardiovascular Care Association. European society of cardiology-acute cardiovascular care association position paper on acute heart failure: a call for interdisciplinary care. Eur Heart J Acute Cardiovasc Care. 2017;6:81-6. doi: $10.1177 / 2048872615593279$.

2. Verbelen $T$, van Cromphaut S, Rega $F$, Meyns B. Acute left ventricular failure after bilateral lung transplantation for idiopathic pulmonary arterial hypertension. J Thorac Cardiovasc Surg. 2013;145:e7-9. doi: 10.1016/j.jtcvs.2012.10.020.

3. Sharma JC, Fletcher S, Vassallo $M$, Ross 
I. Cardiovascular disease and outcome of acute stroke: influence of pre-existing cardiac failure. Eur J Heart Fail. 2000;2:14550. doi: 10.1016/S1388-9842(00)00067-2.

4. Webb AR. Management of acute heart failure. Minerva Anestesiol. 2002;68:196200. PMID: 12024082.

5. Zhang $H$, Cao $Y$, Chen $L$, Wang J, Tian $Q$, Wang N, Liu Z, Li J, Wang N, Wang X, Sun P, Wang $L$. A polysaccharide from Polygonatum sibiricum attenuates amyloid- $\beta$-induced neurotoxicity in PC12 cells. Carbohydr Polym. 2015;117:879-86. doi: 10.1016/j. carbpol.2014.10.034.

6. Long T, Liu Z, Shang J, Zhou X, Yu S, Tian H, Bao Y. Polygonatum sibiricum polysaccharides play anti-cancer effect through TLR4MAPK/NF-KB signaling pathways. Int J Biol Macromol. 2018;111:813-21. doi: 10.1016/j. ijbiomac.2018.01.070.

7. Zhang $H$, Cao $Y$, Chen L, Wang J, Tian $Q$, Wang N, Liu Z, Li J, Wang N, Wang X, Sun P, Wang $L$. A polysaccharide from Polygonatum sibiricum attenuates amyloid- $\beta$-induced neurotoxicity in PC12 cells. Carbohydr Polym. 2015;117:879-86. doi: 10.1016/j. carbpol.2014.10.034.

8. Wang Y, Qin S, Pen G, Chen D, Han C, Miao C, Lu B, Su C, Feng S, Li W, Han J, Cho NC, Si Y. Original Research:Potentialocularprotection and dynamic observation of Polygonatum sibiricum polysaccharide against streptozocin-induced diabetic rats' model. Exp Biol Med (Maywood). 2017;242:92-101. doi: $10.1177 / 1535370216663866$.

9. Cui X, Wang $S, \mathrm{Cao} H$, Guo H, Li Y, Xu F, Zheng $M, X i X$, Han C. A review: the bioactivities and pharmacological applications of polygonatum sibiricum polysaccharides. Molecules. 2018;23:pii: E1170. doi: 10.3390/molecules23051170.

10.Zhou L, Chen L, Wang J, Deng Y. Astragalus polysaccharide improves cardiac function in doxorubicin-induced cardiomyopathy through ROS-p38 signaling. Int J Clin Exp Med. 2015;8:21839-48. PMID: 26885153.

11.Chen W, Yu MH, Li YM, Chen WJ, Xia YP. Beneficial effects of astragalus polysaccharides treatment on cardiac chymase activities and cardiomyopathy in diabetic hamsters. Acta Diabetol. 2010;47:35-46. doi: 10.1007/s00592-0090116-5.
12.Tomonari $M$, To $H$, Nishida $M$, Mishima T, Sasaki H, Kurose H. Mechanism of the cardioprotective effects of docetaxel pre-administration against adriamycininduced cardiotoxicity. J Pharmacol Sci. 2011;115:336-45. PMID: 21358119.

13. Kusuoka H, Futaki S, Koretsune Y, Kitabatake A, Suga $H$, Kamada T, Inoue M. Alterations of intracellular calcium homeostasis and myocardial energetics in acute adriamycininduced heart failure. J Cardiovasc Pharmacol. 1991;18:437-44. PMID: 1720844.

14.Koenig W. Heart disease and the inflammatory response. BMJ. 2000;321:1878. PMID: 10903629.

15.Bradham WS, Moe G, Wendt KA, Scott AA, Konig A, Romanova M, Naik G, Spinale FG. TNF-alpha and myocardial matrix metalloproteinases in heart failure: relationship to LV remodeling. Am J Physiol Heart Circ Physiol. 2002;282:H1288-95. doi: 10.1152/ajpheart.00526.2001.

16.Birner CM, Ulucan C, Fredersdorf $S$, Rihm M, Löwel H, Stritzke J, Schunkert $\mathrm{H}$, Hengstenberg C, Holmer S, Riegger G, Luchner A. Head-to-head comparison of BNP and IL- 6 as markers of clinical and experimental heart failure: superiority of BNP. Cytokine. 2007;40:89-97. doi: 10.1016/j.cyto.2007.08.009.

17.Li W, Olshansky B. Inflammatory cytokines and nitric oxide in heart failure and potential modulation by vagus nerve stimulation. Heart Fail Rev. 2011;16:137-45. doi: 10.1007/s10741-010-9184-4.

18.Freeman LM, Rush JE, Milbury PE, Blumberg JB. Antioxidant status and biomarkers of oxidative stress in dogs with congestive heart failure. J Vet Intern Med. 2005;19:53741. PMID: 16095171.

19.Su X, Ma Y, Huang $R$, Wang $X$, Wang $Y$. Effects of shenmai injection on blood SOD activity and MDA level in senile patients with coronary heart disease. J Tradit Chin Med. 2005;25:50-3. PMID: 15889524.

20.Joe B, Lokesh BR. Studies on the inactivation of superoxide dismutase activity by nitric oxide from rat peritoneal macrophages. Mol Cell Biochem. 1997;168:87-93. PMID: 9062897.

21.Qi YY, Liu K, Zhang J, Li K, Ren JJ, Lin P. Synergic effect of $\mathrm{Na}(+)-K(+)$ ATPaseB1 and 
adriamycin on inhibition of cell proliferation and reversal of drug resistance in breast cancer MCF-7 cells. Ai Zheng. 2009;28:8617. PMID: 19664334.

22.Formentini $L$, Sánchez-Aragó $M$, Sánchez-Cenizo L, Cuezva JM. The mitochondrial ATPase inhibitory factor 1 triggers a ROS-mediated retrograde prosurvival and proliferative response. Mol Cell. 2012;45:731-42. doi: 10.1016/j. molcel.2012.01.008.

23.King A, Selak MA, Gottlieb E. Succinate dehydrogenase and fumarate hydratase: linking mitochondrial dysfunction and cancer. Oncogene. 2006;25:4675-82. doi: 10.1038/sj.onc.1209594.

24.Tokudome T, Horio T, Yoshihara F, Suga $S$, Kawano $Y$, Kohno $M$, Kangawa K. Adrenomedullin inhibits doxorubicininduced cultured rat cardiac myocyte apoptosis via a cAMP-dependent mechanism. Endocrinology. 2002;143:351521. doi: 10.1210/en.2002-220233.

25.Lu HF, Chie YJ, Yang MS, Lee CS, Fu JJ, Yang JS, Tan TW, Wu SH, Ma YS, Ip SW, Chung JG. Apigenin induces caspase-dependent apoptosis in human lung cancer A549 cells through $\mathrm{Bax}$ - and $\mathrm{Bcl}$-2-triggered mitochondrial pathway. Int J Oncol. 2010;36:1477-84. PMID: 20428772.

26.Lam TT, Abler AS, Tso MO. Apoptosis and caspases after ischemia-reperfusion injury in rat retina. Invest Ophthalmol Vis Sci. 1999;40:967-75. PMID: 10102294.

27. Mei JM, Niu CS. Effects of CDNF on 6-OHDA-induced apoptosis in PC12 cells via modulation of $\mathrm{Bcl}-2 / \mathrm{Bax}$ and caspase-3 activation. Neurol Sci. 2014;35:1275-80. doi: 10.1007/s10072-014-1700-1.

\section{Correspondence:}

Dr. Xiuying Zhu

Department of Emergency Medicine, The First Affiliated Hospital of Xinxiang Medical University

88 Jiankang Road

Weihui, Xinxiang 453100 China

Phone: +86-373-4402543

zhuxiuyinghn@126.com

Received: June 06, 2018

Review: Aug 09, 2018

Accepted: Sept 04, 2018
Conflict of interest: none

Financial source: none 